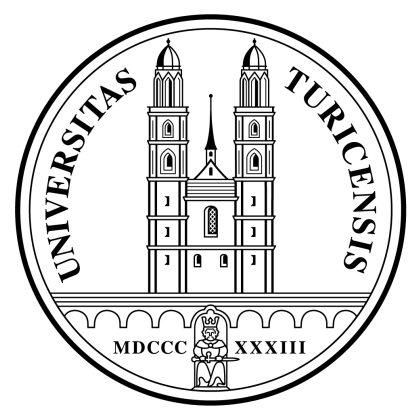

Institute for Empirical Research in Economics

University of Zurich

Working Paper Series

ISSN 1424-0459

Forthcoming in:

Advances in Experimental Business Research, ed by Rami Zwick und Amnon Rapoport,

Kluwer Academic Publishers.

Working Paper No. 62

Work motivation, institutions, and performance

Simon Gächter and Armin Falk

October 2000 


\title{
Work motivation, institutions, and
}

\author{
performance*
}

\author{
SIMON GÄCHTER $^{+}$AND ARMIN FALK $^{++}$
}

October 2000

\begin{abstract}
In this paper we study experimentally four remedies to overcome inefficiencies that arise from the incompleteness of contracts. These remedies are reciprocity, repeated game effects, social embeddedness, and incentive contracts. In our baseline treatment we find that reciprocity is a powerful contract enforcement device. A second experiment establishes that repeated game effects interact with reciprocity in a complementary way, i.e., efficiency is increased compared to our baseline. Adding social approval incentives does not contribute significantly to efficiency. Finally, we show that explicit incentive contracts may have perverse effects in the sense that they "crowd out" reciprocity and therefore reduce efficiency compared to the baseline. In our concluding section we discuss the relation of our findings to the recent literature on "intrinsic motivation".
\end{abstract}

JEL-Classification: D64, J30, J50, J64, C92

\footnotetext{
* This paper is part of the EU-TMR Research Network ENDEAR (FMRX-CT98-0238). We gratefully acknowledge financial support from the Swiss National Science Foundation (No. 1214-051000.97) and from the MacArthur Foundation, Network on Economic Environments and the Evolution of Individual Preferences and Social Norms. For helpful comments we are grateful to Werner Güth, Amnon Rapoport and the participants of the First Asian Conference on Experimental Business Research at the Hong Kong University of Science and Technology.

${ }^{+}$University of St. Gallen, Dufourstrasse 50b, CH-9000 St. Gallen. E-mail: simon.gaechter@unisg.ch

${ }^{++}$University of Zürich, Institute for Empirical Research in Economics, Blümlisalpstrasse 10, CH-8006 Zürich. E-mail: falk@iew.unizh.ch
} 


\title{
1. Incomplete contracts and the problem of work motivation
}

\author{
“... motivation problems arise only because some plans \\ cannot be described in a complete, enforceable contract." \\ Milgrom and Roberts (1992, p. 127) \\ "A thorough understanding of internal incentive structures is \\ critical [...], since these incentives determine to a large \\ extent how individuals inside an organization behave."
}

Baker, Jensen and Murphy (1988, p. 593)

Many economically important contracts are incomplete. This holds in particular for the employment relationship. Very often the labor contract just stipulates a wage payment and leaves out many details that actually determine performance (see, e.g., Baker, Jensen, and Murphy (1988)). Under conditions of incompletely specified obligations and only weak or absent explicit performance incentives the issue of motivation arises.

Let us start with a simple model, which describes the motivational problem that arises with incomplete contracts. In the main part of the present paper we will study experimental versions of this model. Suppose that a principal stipulates a contract that specifies a wage $w$ and a desired effort level $\hat{e}$. Assume further that the principal's profit increases with the effort level. The principal can assure at most an effort level of $e_{0}$ from selfish and rational agents, i.e., only $e_{0}$ is "enforceable" via third parties like courts. The employment contract in this situation is incomplete since the principal cannot condition the wage payment on effort. The desired performance level $\hat{e}$ is just "cheap talk". Since effort is costly for the agent due to some disutility $c(e)>0$ (with $c^{\prime}(e)>0$ ), it follows that, in case of $\hat{e}>e_{0}$, an agent who reduces effort below $\hat{e}$ will increase her net utility. Therefore, a rational profitmaximizing principal facing a selfish and rational agent cannot enforce $e>e_{0}$. How can principals in such a situation motivate their employees to work harder? Of course, this is an important question for the economics of organizations and for firms' employment policies.

This paper tries to shed light on ways to influence performance decisions under incomplete contracts. Actual human behavior within organizations is most likely influenced by conventions and social norms, intrinsic motivation, the striving for social approval, but also by the material incentives that are provided by payment schemes and the duration of the relationship. Many scholars have pointed out aspects of these arguments (see, e.g., Leibenstein (1979), Baker, Jensen, and Murphy (1988), Simon (1991), Lazear (1991), Frey (1997), Schlicht (1998), Malcomson and MacLeod (1998), Bewley (1999)).

In the main part of our paper we compare four potential remedies of contractual incompleteness: reciprocity-based voluntary cooperation (Section 2), repeated interaction (Section 3), social embeddedness (Section 4), and incentive contracts (Section 5). To achieve the comparison, we enrich the basic situation described above by varying the institutional environment. In our synopsis we draw on data collected by Fehr, Gächter, and Kirchsteiger (1997), Falk, Gächter and Kovács (1999) and Fehr and Gächter (2000), who analyzed different aspects of the contract enforcement problem in isolation. Our 
comparison of the institutional variations allows us to assess the behavioral impact of various incentive structures.

The main results of our comparative analysis are as follows: First, reciprocity-based voluntary cooperation clearly is a crucial motivation in all the experiments we investigate here. Second, the effectiveness of voluntary cooperation to improve performance depends on institutional and contractual arrangements: Enhanced possibilities for reciprocity, as they are, for instance, provided by a repeated interaction, considerably improve performance. Social exchange does not contribute to higher effort levels than those achieved with anonymous repeated interactions. Financial incentives in the form of a contractually determined wage cut in case of detected shirking, "crowd out reciprocity" and induce opportunism. In our concluding section we discuss some interesting links between our investigation of interaction effects of material incentives on people's propensity for voluntary cooperation, and the literature on "crowding out of intrinsic motivation", which has received considerable attention among practitioners as well as among academics interested in the effectiveness of incentive systems.

\section{Remedy I: Voluntary cooperation}

"A norm of reciprocity is, I suspect, no less universal and important an element of culture than the incest taboo (...)."

Alvin Gouldner (1960, p. 171)

Organizational theorists as well as personnel managers often stress the importance of an agent's general job attitude. For example, Williamson (1985) argues that under incomplete employment contracts "consummate cooperation" becomes important. He defines "consummate cooperation" as opposed to merely "perfunctory cooperation" as "an affirmative job attitude whereby gaps are filled, initiative is taken, and judgment is exercised in an instrumental way" (Williamson (1985), p. 262). Hence, in a work context that is incompletely specified, to behave "cooperatively", by showing "initiative" and "good judgment", may well be the particular expression of a reciprocal motivation that applies in the situation at hand.

How can the existence of reciprocity help the principal to elicit effort levels above $e_{0}$ ? Roughly speaking, reciprocity means that people reward kind acts and punish unkind ones. Let us assume that the kindness of a certain contract offer $(w, \hat{e})$ is determined by the rent the agent receives from the principal. This rent arises from the offer $(w, \hat{e})$ minus the opportunity costs of accepting $(w, \hat{e})$. If an agent is motivated by reciprocity considerations she will choose higher levels of $e$ the higher the offered rent is. Thus, by offering sufficiently high rents principals may be capable of eliciting effort levels above $e_{0}{ }^{1}$

\footnotetext{
${ }^{1}$ From a psychological perspective there may be several reasons for agents' willingness to respond reciprocally, like equity considerations (Güth (1994)); inequity aversion (Fehr and Schmidt (1999), Bolton and Ockenfels (2000); intentions (Rabin (1993), Dufwenberg and Kirchsteiger (2000)); or a combination of inequity aversion and intentions (Falk and Fischbacher (1999))
} 
The experimental design. In the following section we present an experiment that was designed to test the potential role of reciprocity as a contract enforcement device. ${ }^{2} \mathrm{We}$ describe this design in some detail because all other experiments reported in this paper are modifications of this design.

At the beginning of the experiment subjects were randomly allocated to their roles as "principals" and "agents". They played a version of the so-called "gift-exchange game" introduced by Fehr, Kirchsteiger and Riedl (1993). The first stage is a posted-bid-market. Subjects in the role of a principal post an employment contract that consists of a wage and a desired effort level $\hat{e}$. Wages have to be integers between 0 and 100 and the available effort levels are between 0.1 and 1 with increments of 0.1 (see Table 1).

TABLE 1: Effort levels and costs of effort

\begin{tabular}{ccccccccccc}
\hline $\boldsymbol{e}$ & $\mathbf{0 . 1}$ & $\mathbf{0 . 2}$ & $\mathbf{0 . 3}$ & $\mathbf{0 . 4}$ & $\mathbf{0 . 5}$ & $\mathbf{0 . 6}$ & $\mathbf{0 . 7}$ & $\mathbf{0 . 8}$ & $\mathbf{0 . 9}$ & $\mathbf{1}$ \\
\hline $\boldsymbol{c}(\boldsymbol{e})$ & 0 & 1 & 2 & 4 & 6 & 8 & 10 & 12 & 15 & 18 \\
\hline \hline
\end{tabular}

In a given period, each principal can offer only one employment contract. After principals submit their contract offers, subjects in the role of agents, who accepted a contract, have to make an actual effort decision at the second stage of the game. An agent's choice of an effort level is associated with costs for the agent as indicated in Table 1. Principals also know Table 1. ${ }^{3}$ After principals are informed about the effort decision of 'their' agent, the second stage is completed and payoffs can be calculated. An agent's payoff at the end of the second stage is given by

$$
\begin{array}{ll}
u=w-c(e) & \text { upon acceptance } \\
u=0 & \text { otherwise }
\end{array}
$$

where $w$ denotes the accepted wage and $c(e)$ the costs of the agent's actual effort. In case an agent does not trade, she earns nothing. A principal's payoff is given by

$$
\begin{array}{lll}
\pi=v e-w & & \text { upon acceptance } \\
\pi=0 & & \text { otherwise }
\end{array}
$$

where $v$ denotes a principal's redemption value, i.e., the maximal gross profitability of an agent for the principal (provided $e=1$ ). The redemption value $v$ was set at 100 .

\footnotetext{
${ }^{2}$ For further details, see Fehr, Gächter and Kirchsteiger (1997), in particular Section 6.

${ }^{3}$ For simplicity the cost of the minimal effort was normalised to "zero". "Effort" can be interpreted as the monetary equivalent of the standard assumption of disutility of work, which increases in the effort level. The important point of both design features, the "normalisation" and the monetary costs, is that they set incentives that can be thought of being "isomorphic" to real world effort choices that are perceived as being onerous. See van Dijk, Sonnemans and van Winden (forthcoming) for a "real effort" experiment on incentives systems. Moreover, to state the incentive problem as sharply as possible, we deliberately abstract from measurement problems of performance.
} 
Our experimental design incorporates the motivational problem outlined in Section 1. Under the assumption of rationality and selfishness, no agent has an incentive to choose an effort level above 0.1 regardless of the wage payment. Principals, therefore, also have no reason to pay more than $w^{*}=1$, which is just enough to induce a selfish agent to accept the contract.

Above we have argued that reciprocal voluntary cooperation may be an important contract enforcement device under conditions of incomplete contracts. Notice that in the two-stage-design described above it is basically the agents who have the opportunity to respond reciprocally to a principal's offer. However, most actual labor relations are longterm relationships and principals have opportunities to react to an agent's effort decision. For example, principals usually have many possibilities to influence an agent's utility of a given job, e.g., via promotion policies, access to fringe benefits, bonuses, and social sanctioning. To allow for the possibility that principals can respond to the agents' choices, Fehr, Gächter, and Kirchsteiger (1997) introduced a third stage into their design, in which principals have the opportunity to either punish or reward their agent at some cost. After having learned an agent's effort decision, a principal can choose a punishment/reward variable $p \in\{-1,-0.9, \ldots, 1\}$. To punish $(p<0)$ or to reward $(p>0)$ is costly for a principal. The costs of punishment amount to $10|p|$. Notice that only in case of $p=0$, i.e., if the principal neither rewards nor punishes, no costs arise. A punishment reduces the agent's gain at the end of the second stage by $25 p$ whereas a reward gives the agent an additional payment of $25 p$. To get some insight into agents' expectation formation when determining their actual effort at the second stage, agents in the three-stage treatment have to indicate the punishment/reward level $p^{e}$ they expect from their principal, given their effort decision. Principals are not informed about the expected punishment/reward level. Notice that, since to punish or to reward is costly, the addition of a third stage does not alter the predictions derived under the assumption of rationality and selfishness.

In both the two- and three-stage treatment, agents and principals conclude contracts on a market. Principals post the contracts and agents choose among the available ones in a randomly determined order. Moreover, to induce competition among agents, there are more agents than principals (6 principals and 8 agents). After a two- or three-stage sequence is concluded, a new "trading day" starts where new principal-agent pairs are matched (in total there were twelve trading days). A total of 56 subjects participated in these experiments.

Procedures (of all experiments reported in this paper). After subjects' roles (which they kept throughout the whole experiment) were randomly determined, principals and agents were located in two different, yet adjacent, large rooms in which they sat remote from each other. They were given their written instructions, which included a set of control questions. The experiments did not start until all subjects answered all questions correctly. We can, therefore, safely assume that subjects fully understood the calculation of payoffs. Procedures and payoff functions were common knowledge, i.e., they were explained in the instructions and it was emphasized that they were the same for all principals and agents, 
respectively. Moreover, to ensure common knowledge, an experimenter orally summarized procedures and payoff functions.

All experiments reported in this paper were conducted manually. In two experiments (remedies I and IV), the "matching" of principals and agents was done in a market; in remedies II and III, the matching occurred in a bilateral trading institution. In the market experiments principals orally submitted wage offers, which were transferred to the agents' room and there written on a chalkboard. Agents saw all wages and could then decide whether they wanted to accept them. In the bilateral trading institutions, principals made their wage offers by inserting them privately into their decision sheets. Then an experimenter collected the wage offers and transmitted them to the agents' room. Here, only the agent matched with a particular principal was informed about "her" principal's wage offer (a second experimenter in the agents' room wrote the wage offer into the agents' documentation sheets). After wages were settled, the agents made their effort choices in privacy. In all experiments, only the particular principal an agent was matched with was informed about it. Finally, principals and agents had to calculate profits. This ended a period. In all experiments (except those reported in the context of remedy III), identities of trading partners were never revealed and subjects were informed that they would never learn a trading partner's identity.

The experiments were conducted with students from different fields (except economics). They lasted between 1.5 and 2.5 hours. All subjects were paid according to their decisions and earned on average more than the opportunity cost of a typical students' job.

Hypotheses and Results. A first impression of the results is given by the summary statistics in Table 2, which reveals that the predictions of wages close to zero and effort levels of 0.1 are clearly refuted. Average wages and demanded effort levels are similar in both treatments. Moreover, principals' contractual offers are more homogeneous in the three-stage treatment (compare the standard deviations).

TABLE 2: Contractual behavior - Summary statistics

\begin{tabular}{cccc}
\hline & Wage & $\begin{array}{c}\text { effort } \\
\text { demanded } \hat{\boldsymbol{e}}\end{array}$ & $\begin{array}{c}\text { actual } \\
\text { effort } \boldsymbol{e}\end{array}$ \\
\cline { 2 - 4 } 2-stage treatment & 30.1 & 0.65 & 0.37 \\
& $(17.7)$ & $(0.27)$ & $(0.26)$ \\
3-stage treatment & 27.3 & 0.72 & 0.63 \\
& $(7.2)$ & $(0.13)$ & $(0.28)$ \\
\hline \hline
\end{tabular}

Note: Entries are averages over all twelve periods. Numbers in parentheses are standard deviations. Source: Fehr et al. (1997) and own calculations.

Table 2 also shows that the contract enforcement problem is lowest in the three-stagetreatment. Thus, behaviorally, principals' punishment and reward possibilities at the third 
stage were obviously credible. But even in the absence of punishment and rewards, on average, agents provided above-minimum effort levels.

In order to make the concept of agents' reciprocity measurable, it is necessary to define the kindness of an action. In our context, the rent $r=w-c(\hat{e})$ that is offered to the agents can be taken as an indicator of 'generosity' (because it measures the excess payment over the necessary compensation of the disutility of the demanded effort). By the same token, the actual effort level indicates the kindness of an agent. Reciprocity, therefore, means that agents choose higher effort levels if principals offer them higher rents. Of course, actual effort behavior may also be correlated with expected punishments or rewards, respectively. We summarize these arguments in the following

\section{RECIPROCITY HYPOTHESES:}

1. The offered rent is positively related to the demanded effort level.

2. Agents' actual effort choice will increase in the offered rent. In the three-stage treatment, agents' actual effort will also depend positively on the expected punishment/reward $\mathrm{p}^{\mathrm{e}}$.

3. Principals (i) punish less, the less agents deviate negatively from $\hat{\mathrm{e}}$, and (ii) they reward more, the more agents deviate positively from $\hat{\mathrm{e}}^{4}$

Table 3 documents the formal regression models that we have used to test our behavioral hypotheses. The table reports three basic models. They relate directly to our behavioral hypotheses (1) to (3). Except for punishment and reward, the same models have been separately estimated for the two- and the three-stage treatments.

The results on Hypothesis (1) show that principals behaved differently in the two treatments. In the two-stage treatment principals appealed to agents' reciprocity since their offered rent increased in the demanded effort level. This was not the case in the three-stage treatment. In the latter, principals paid rents but their rent offers did not increase in the desired effort level. To the contrary, rents even declined in the effort level. However, the $\chi^{2}$-statistic for the 3 -stage model reveals that this model has no explanatory power. Hence, we conclude that principals' rent offers were more or less constant. Principals' strategic position is improved in the three-stage treatment since here principals have the 'last word to say'.

In the two-stage treatment, point 2 of our Reciprocity Hypothesis is confirmed by our data. Agents reciprocated higher offered rents with higher actual effort levels since the coefficient on the offered rent is positive and highly significant. In the three-stage treatment, agents' actual effort choice did not significantly depend on the offered rent (although the coefficient is positive), but agents reacted highly positively to the expected punishment or reward. The lower the expected punishment or the higher the expected reward, the higher was the actual effort level.

\footnotetext{
${ }^{4}$ Formally this means that $(e-\hat{e})$ and $p^{e}$ are expected to be positively correlated.
} 
TABLE 3: Evidence on the Reciprocity Hypotheses

\begin{tabular}{|c|c|c|c|c|c|}
\hline \multirow{2}{*}{$\begin{array}{r}\text { Dependent } \\
\text { variables }\end{array}$} & \multicolumn{2}{|c|}{ offered rent } & \multicolumn{2}{|c|}{ actual effort } & \multirow{2}{*}{$\begin{array}{c}\text { punish/ } \\
\text { reward } \\
p \\
(3)\end{array}$} \\
\hline & \multicolumn{2}{|c|}{$r$} & \multicolumn{2}{|c|}{$e$} & \\
\hline $\begin{array}{l}\text { Explanatory } \\
\text { variables: }\end{array}$ & 2-stage & 3-stage & 2-stage & 3-stage & 3-stage \\
\hline Constant & $\begin{array}{c}-0.671 \\
(1.54)\end{array}$ & $\begin{array}{c}21.496^{* * *} \\
(3.122)\end{array}$ & $\begin{array}{l}-0.066^{*} \\
(0.037)\end{array}$ & $\begin{array}{c}0.423^{* * *} \\
(0.056)\end{array}$ & $\begin{array}{c}0.277 * * * \\
(0.031)\end{array}$ \\
\hline $\boldsymbol{e}$ & $\begin{array}{c}37.948 * * * \\
(2.228)\end{array}$ & $\begin{array}{l}-6.521 \\
(4.416)\end{array}$ & - & - & - \\
\hline$r$ & - & - & $\begin{array}{c}0.021 * * * \\
(0.001)\end{array}$ & $\begin{array}{c}0.004 \\
(0.003)\end{array}$ & - \\
\hline$p^{e}$ & - & - & - & $\begin{array}{c}0.578^{* * * *} \\
(0.057)\end{array}$ & - \\
\hline $\boldsymbol{e}-\hat{\boldsymbol{e}}$ & - & - & - & - & $\begin{array}{c}1.554 * * * \\
(0.151) \\
\end{array}$ \\
\hline $\mathrm{N}$ & 141 & 141 & 141 & 141 & 141 \\
\hline Log-L & -481.9 & -473.8 & -37.2 & -31.7 & $\mathrm{R}^{2}=0.54$ \\
\hline$x^{2}$ & $275.0 * * *$ & 2.18 & $138.0 * * *$ & $110.0 * * *$ & $\mathrm{~F}=105.2 * * *$ \\
\hline
\end{tabular}

Note: Since our dependent variables are censored below and above, the estimation procedure is censored regression. Since data are not independent within a session, we calculate robust standard errors with session as the independent unit. Model (3) is estimated with 2SLS (with rent and $p^{e}$ as instruments), since (e-ê) is endogenously determined. The robust standard errors are in parentheses. ${ }^{*}$ denotes significance at the 10 percent level, $* *$ at the 5-percent level and $*^{* *}$ at the 1-percent level. $\hat{e}$ denotes demanded effort, $c(\hat{e})$ are the implied effort costs (see Table 1), $r$ denotes the offered rent (i.e., $w-c(\hat{e})$ ), and $p^{e}$ is the agents' expected punishment/reward level. N denotes the number of observations. Data source: Fehr et al. (1997).

Point 3 of our Reciprocity Hypothesis concerns principals' punishment and reward behavior at the third stage. An inspection of the right-hand column of Table 3 reveals that the effort deviation $e-\hat{e}$ was of overwhelming importance. The higher this deviation was, i.e., the less severe the contract enforcement problem, the higher was the reward or the lower was the punishment. This result shows that principals behaved reciprocally just as the agents. This fact had interesting and unexpected implications at the previous two stages. At the second stage, agents did not respond reciprocally but chose their effort level, quite rationally, given their correct expectations about principals' reciprocal propensity to reward or to punish. Consistent with this behavior, at the first stage, principals did not increase their offered rents in the desired effort level. Quite the contrary, the higher their demanded effort level was, the less generous was their job offer.

It is important to note that the observed reciprocity is not just the result of aggregating over all decisions. A detailed analysis at the individual level shows that, for instance in the two-stage treatment, roughly 60 percent of the agents exhibit a significantly positive renteffort pattern (according to Spearman rank correlations). In the remainder of this paper, we take the observed amount of reciprocity-driven voluntary cooperation as a benchmark and 
focus on the question of how agents' voluntary cooperation is affected by extrinsic incentives.

\section{Remedy II: Long-term contracts}

"... the two key requisites for co-operation to thrive are that the co-operation be based on reciprocity, and that the shadow of the future is important enough to make this reciprocity stable."

Robert Axelrod (1984, p. 173)

Labor relations can rarely be viewed as spot market transactions where anonymous trading partners interact only once. Rather, employers and employees often play a repeated game that opens up the possibility for implicit contracts and repeated game incentives (see, e.g. MacLeod and Malcomson (1998)). As Remedy I has shown, reciprocity-driven voluntary cooperation can mitigate the contract enforcement problem. Since a repeated interaction provides - in principle - material incentives for cooperation, the question arises whether these repeated game incentives are, indeed, compatible with reciprocal motivations. In the following, we describe an experiment that extends the design discussed above to allow for repeated interactions.

Experimental design. The main treatment change compared to the 2-stage design described above is the following: Instead of interacting in a one-shot market, randomly matched principals and agents remain paired for ten periods. To control for the mere impact of repeated interaction, we compare the outcome of this treatment with a treatment where subjects were re-matched with ten different opponents. Thus, there were two treatments, a so-called "Stranger"-treatment, where subjects interacted only once, and a "Partner"-treatment, where subjects played a finitely repeated gift-exchange game. ${ }^{5}$ The matching protocol was explained in the instructions and verbally emphasized in front of all subjects. A post-experimental debriefing confirmed the credibility of both matching protocols. In total, 90 subjects participated in this study.

Hypotheses and Results. In this finitely repeated gift exchange game agents who are not motivated by reciprocity may have an incentive to imitate reciprocity in order to build a reputation for being a reciprocator. However, the repeated interaction may also foster intrinsic reciprocity because a repeated interaction may create a chain of reciprocal obligations. Hence, in the Partner-treatment, we should observe at least as much reciprocity as in the Stranger-treatment, because reciprocal behavior for reputational reasons may add to (foster) intrinsic reciprocity (for a further discussion see Falk et al. (1999)).

\footnotetext{
${ }^{5}$ For further procedural details and experimental instructions see Falk et al. (1999).
} 


\section{THE REPEATED INTERACTION HYPOTHESIS:}

1. Wages and effort levels are positively correlated. In the Stranger-treatment, this measures the true amount of intrinsic reciprocity that may be present in all treatments. In the Partner-treatment, intrinsic reciprocal behavior may be confounded with extrinsic incentives. In particular, we hypothesize that the aggregate wage-effort relationship in the Partner-treatment is at least as steep as in the Stranger-treatment.

2. As a result, efforts in the Partner-treatment are-for a given wage-at least as high as in the Stranger-treatment.

TABLE 4: Voluntary cooperation in repeated interactions with social incentives (for Remedy III - see next section)

\begin{tabular}{|c|c|c|c|c|}
\hline \multicolumn{5}{|c|}{ dependent variable: effort } \\
\hline & \multicolumn{2}{|c|}{$\begin{array}{c}\text { Remedy II } \\
\text { (Repeated Interaction) }\end{array}$} & \multicolumn{2}{|c|}{$\begin{array}{c}\text { Remedy III } \\
\text { (Social embeddedness) }\end{array}$} \\
\hline Treatment: & $(1)$ & $(2)$ & (3) & $(4)$ \\
\hline $\begin{array}{l}\text { Indep- } \\
\text { endent } \\
\text { variables: }\end{array}$ & "Stranger" & "Partner" & $\begin{array}{l}\text { "Approval } \\
\text { face to face" }\end{array}$ & $\begin{array}{c}\text { "Approval } \\
\text { social pressure" }\end{array}$ \\
\hline constant & \multicolumn{4}{|c|}{$\begin{array}{l}-0.421^{* * *} \\
(0.1400)\end{array}$} \\
\hline $\begin{array}{l}\text { Wage } x \\
\text { Treatment }\end{array}$ & $\begin{array}{l}0.016^{* *} \\
(0.0021)\end{array}$ & $\begin{array}{c}0.0202 * * * \\
(0.0024)\end{array}$ & $\begin{array}{c}0.019 * * * \\
(0.0027)\end{array}$ & $\begin{array}{c}0.017 * * * \\
(0.0027)\end{array}$ \\
\hline & & $\begin{array}{r}\mathrm{N}=61 \\
\log -\mathrm{L}=-3 \\
\chi^{2}=71.2\end{array}$ & & \\
\hline
\end{tabular}

Note: Since our dependent variables are censored below and above, the estimation procedure is censored regression. Since data are not independent within a session (or bargaining pair, resp.), we calculate robust standard errors with session (in (1)) and bargaining pairs (in (2) - (4)) as the independent units. Forty subjects participated in the Stranger-treatment; in the Partner-treatment we had 25 independent pairs, and in the Approval treatments a total of 18 independent pairs participated in the experiments. We pool the data of all treatments and construct the independent variable as an interaction variable of wage and the respective treatment dummy. The treatments that relate to (3) and (4) are discussed in the next section. Data source: Falk et al. (1999), and own calculations.

In the regression model presented in Table 4 the wage coefficient in the Stranger-treatment measures the slope of the wage-effort relationship. Agents in the Stranger-treatment clearly exhibit reciprocal behavior since the wage coefficient is positive and highly significant. This replicates the results of the two-stage treatment reported above. As further analyses have shown, there have been no significant spillovers between periods in the Strangertreatment. Therefore, we take this coefficient to be the benchmark of genuine reciprocity, which is achieved in the absence of any extrinsic incentives. 
The Repeated Interaction Hypothesis predicts a wage-effort relationship in the Partner-treatment that is at least as steep as in the benchmark of the Stranger-treatment. Column (2) shows that the wage-effort relation is steeper in the Partner- than in the Stranger-treatment. A $\chi^{2}$-test confirms that the coefficient in the Partner-treatment is, indeed, significantly higher than in the Stranger-treatment.

The results show that the repeated interaction has fostered reciprocal behavior. Consequently, average effort levels should - for a given wage - be higher in the Partnertreatment than in the Stranger-treatment. Table 5 shows that this is, indeed, the case. Whereas wages are almost identical across treatments, effort levels and thus efficiency are clearly higher in the Partner-treatment.

TABLE 5: Contract performance with and without repeated interaction and with social incentives (for Remedy III - see next section)

\begin{tabular}{ccccccccc}
\hline & \multicolumn{3}{c}{$\begin{array}{c}\text { Remedy II } \\
\text { (Repeated Interaction) }\end{array}$} & \multicolumn{4}{c}{$\begin{array}{c}\text { Remedy III } \\
\text { (Social embeddedness) }\end{array}$} \\
& "Stranger" & \multicolumn{2}{c}{ "Partner" } & \multicolumn{2}{c}{ “Approval } & \multicolumn{2}{c}{ "Approval } \\
face to face" & social pressure" \\
\cline { 2 - 9 } & Wage & effort & wage & effort & wage & effort & wage & effort \\
Mean & 60.6 & 0.53 & 66.0 & 0.76 & 63.9 & 0.71 & 62.4 & 0.75 \\
(std.dev.) & $(11.6)$ & $(0.31)$ & $(11.7)$ & $(0.23)$ & $(18.4)$ & $(0.25)$ & $(11.4)$ & $(0.26)$ \\
\hline \hline
\end{tabular}

In summary, we conclude that a long-term interaction is quite an effective tool to induce better contractual performance. An analysis of individual behavior sheds light on the reasons for this observation. In both the Partner- and the Stranger-treatment, there is a majority of subjects who is genuinely motivated by reciprocity. Sixty percent of the agents in the Stranger-treatment and even 72 percent of the agents in the Partner-treatment exhibit a significantly positive wage-effort relationship (according to Spearman rank correlations). Thus, the repeated interaction "crowds in" reciprocity. In a certain sense, both standard economic theory and reciprocity theory have a point in case. It is the interaction of both forces - the incentives provided by mere repeated interaction, and the social norm of reciprocity - that jointly mitigate the contract enforcement problem quite effectively. ${ }^{6}$

\footnotetext{
${ }^{6}$ See Gächter and Falk (1999) for a detailed analysis of individual behavior in repeated and one-shot giftexchange games.
} 


\section{Remedy III: Social embeddedness}

"When we seek economic goals in our interactions with others, these are usually
combined with striving for sociability, approval, status, and power as well."

Mark Granovetter (1992, p. 234)

A natural feature of most real life employment relations is that they are characterized by social interactions. In most instances, work does not take place in a social vacuum, i.e., under completely anonymous conditions. Instead, employers and employees personally interact with each other. This social interaction may create yet another form of extrinsic incentives beyond those of the repeated interaction, namely, the expectation of emotionally prompted social approval or disapproval. The sociologist Peter Blau (1964) argues that social approval is a basic reward that people seek, a fact that is also highlighted by social psychologists. Moreover, a substantial amount of economic production takes place in personalized settings where communication and 'identification' (Bohnet (1997)) allow social control to become effective.

Experimental Design. To test for the impact of social interaction, Falk et al. (1999) implemented two additional treatments. The two treatments varied in the degree of social embeddedness. As in the Partner-treatment, subjects interacted repeatedly. However, anonymity was lifted. In the "Face-to-Face" treatment the two subjects of a principal-agent pair were introduced to each other before they knew the rules of the game. Matched pairs were seated face-to-face. Subjects were not allowed to communicate verbally or with written comments. In the second treatment ("Social pressure"), subjects were again introduced and seated face-to-face. In addition, subjects were told that after the last round of the session they would have a chance for communication and discussion about what had happened during the experiment. Hence, subjects anticipated that after the final period they could exchange social approval and disapproval. Both treatments are thus parsimonious ways of lifting anonymity and inducing social approval and disapproval. ${ }^{7}$

Hypotheses and Results. A natural conjecture is that the approval incentives that are present in this experiment foster reciprocity. The reason is that people may not only feel obliged for intrinsic reasons to react reciprocally. These feelings may be reinforced by the presence of immediate expressions of approval or disapproval or by the expected exertion of social pressure (or approval) at the end of the experiment. Since in the approval treatment approval incentives are added to repeated game incentives, one may conjecture that the reciprocal relationship is strengthened compared to the anonymous Partnertreatment. For the Approval Hypothesis, therefore, the Partner-treatment serves as a baseline.

\footnotetext{
${ }^{7}$ Communication during these experiments was not permitted. The reason is that communication is confounded with social pressure, internalised norms of keeping one's promises, coordination on particular wage and effort levels, etc. (see also Bohnet (1997)). For further discussion and detailed description of procedures see Falk et al. (1999).
} 


\section{THE APPROVAL HYPOTHESIS:}

Wages and effort levels are positively correlated. In all treatments intrinsic reciprocal behavior may be confounded with extrinsic incentives. In particular, we hypothesize

1. The aggregate wage-effort relationship in the Face-to-Face-treatment is at least as steep as in the Partner-treatment.

2. In the Social-Pressure treatment, the wage-effort relation is at least as steep as in the Face-to-face-treatment.

3. As a result of 1 and 2, effort levels should - for a given wage - tend to increase compared to the Partner-treatment.

In columns (3) and (4), of Table 4 we report the results of our regression analysis that tested Points 1 and 2 of the Approval Hypothesis. The data do not support them. In the Face-to-Face treatment we do not find any significant change of the slope of the wageeffort relationship relative to the Partner-treatment. The slope of the wage-effort relation in the Social-Pressure treatment is somewhat (but insignificantly) lower than in the Face-toFace treatment.

Given the results of Table 4, it is no surprise that the role of the approval forces turns out to be limited. Although wages were rather similar in all three repeated game treatments, effort levels are not statistically higher than those achieved in the anonymous interaction of the Partner-treatment (compare Table 5). Hence, in these data approval incentives did not add to what had already been achieved by repeated interaction alone.

A comparison with the results reported in the previous section (compare Remedy II and III in Table 5) suggests that the mere fact that subjects interact repeatedly is capable of mitigating the contract enforcement problem. The approval incentives investigated in this section did not change very much this finding. This also holds at the individual level.

\section{Remedy IV: Incentive Contracts}

"Incentives are the essence of economics."

Canice Prendergast (1999, p.7)

So far we have neglected the possibility of incentive devices, which in reality are frequently used to mitigate the incentive problem. Principal-agent theory, information economics and contract theory, have all developed arguments about how the conflict of interest between agents and principals can be resolved (see Prendergast (1999) for a comprehensive survey).

For simplicity, we discuss the problem of incentive contracting in the framework introduced in Section 1. Suppose a principal has invested in some verification technology which allows with some probability $s>0$ to prove in court that the desired effort level $\hat{e}$ has not been put forward. Of course, if this verification technology works perfectly (i.e., $s$ $=1$ ), the problem of incompleteness ceases to exist. Here, we do not analyze the optimal 
investment into a verification technology. For our purposes, it suffices to assume that the principal's (optimal) investment in its verification technology leads to $0<s<1$. Assume further that the principal offers the following contract: $(w, f, \hat{e})$, where $f$ is a fine the agent has to pay if it can be verified that she has shirked, i.e., $e<\hat{e}$. Under the assumption of risk neutrality, an agent will not shirk (i.e., $e=\hat{e}$ ) if the "no-shirking condition" holds, i.e., if the expected fine exceeds the opportunity cost of not shirking: ${ }^{8}$

$$
s f \geq c(\hat{e}) .
$$

Obviously, if $f$ were unbounded every effort level $\hat{e}$ could be enforced as long as $s$ is positive. Assume that $f$ is bounded such that less than a maximum feasible effort choice can be enforced. ${ }^{9}$ Then, there exists an optimal effort $\hat{e}^{*} \geq e_{0}$ that can be enforced by an optimal fine $f^{*}$ such that the agent will just choose not to shirk.

Experimental Design. To test for the impact of incentive contracts on actual effort choices, Fehr and Gächter (2000) implemented a treatment that was similar to the stylized model introduced in the preceding paragraph. ${ }^{10}$ This treatment is called "Incentivetreatment". In addition to a wage payment and a desired effort level, principals could also stipulate a fine an agent had to pay in case she was caught shirking (i.e., in case $e<\hat{e}$ ). The detection probability in this experiment was $1 / 3$. The fine had to be chosen from an interval $[0,13]$. Since introducing a fine at any level was costless for the principal, the optimal fine was $f^{*}=13$. Hence, given that the principal actually chose $f^{*}=13$, the expected wage reduction in case of verified shirking was 4.33. This implies that, according to the noshirking condition (and the costs of effort as given in Table 1), principals could elicit at most an effort level of 0.4 (because $c(\hat{e}=0.4)=4$ ). To control for the impact of the incentive contract, Fehr and Gächter (2000) also replicated the two-stage design described in Section 2. They called this treatment the "Trust-treatment". The parameters in the Trust-treatment were the same as in the two-stage treatment of Section 2. One hundred and twenty six subjects participated in these experiments.

Hypotheses and Results. In contrast to the previous institutions and contracts, principals are now in a position to elicit at least $e^{*}>0.1$, where $e^{*}$ denotes the effort that is chosen by selfish and rational individuals, given the fine $f$ and $c(\hat{e})$. For example, in case $f=13$ and $\hat{e}$ $=0.4$, then $e^{*}=0.4$; if $f=10$ and $\hat{e}=0.3$, then $e^{*}=0.3 .^{11}$ In the previous three sections

\footnotetext{
${ }^{8}$ Since, for simplicity, $f$ does not depend on the amount of shirking, an agent who decides to shirk will always shirk fully, i.e., $e=e_{0}$, which implies with our parameters that $c\left(e_{0}\right)=0$.

9 The real world is frequently characterized by constraints on principals' sanction opportunities. Such constraints may be imposed by law or by collective bargaining agreements. They may even arise endogenously because monitoring technologies may not allow the measurement of effort without error or because of problems of principals' moral hazard.

${ }^{10}$ See Fehr and Gächter (2000) for detailed experimental instructions. This paper including instructions is available at http://www.unizh.ch/iew/wp/iewwp034.pdf.

${ }^{11}$ Note that if the no-shirking condition $s f \geq c(\hat{e})$ does not hold (e.g., in case $f=13$ and $\hat{e}>0.4$ ), the optimal effort choice is $e^{*}=0.1$.
} 
we have seen that reciprocity is a major behavioral motivation that actually allowed the principals to elicit $e>e^{*}=0.1$. Therefore, the question arises how performance incentives like those just outlined affect agents' willingness to cooperate or to reciprocate. In other words, are principals able to elicit $e>e^{*}$ ?

One possibility is that reciprocity actually gives rise to extra effort on top of what is enforced by financial incentives alone, i.e., $e-e^{*}>0$, provided principals offer generous rents. Alternatively, it may well be that explicit performance incentives that threaten with a punishment in case of inferior performance, actually reduce the willingness to co-operate voluntarily and lead to effort choices that are at most $e^{*}$. The financial incentives signal distrust and may, hence, "crowd out" voluntary cooperation.

\section{THE CROWDING HyPOTHESES:}

1. In the Trust-treatment the same hypotheses hold as in the two-stage treatment of Section 2.

2. "Crowding In": The reciprocal relationship in the Incentive-treatment is at least as steep as in the Trust-treatment.

3. "Crowding Out": The reciprocal relationship in the Incentive-treatment is less steep as in the Trust-treatment.

To test these hypotheses we have set up the statistical model documented in Table 6. To make the comparison between effort choices in the Trust-treatment and in the Incentivetreatment meaningful, the dependent variable now is $e-e^{*}$, which measures the voluntary effort in excess of agents' selfishly rational effort level $e^{*}$. $^{*}$

The results of Table 6 show that reciprocal behavior in the Trust treatment is similar to the reciprocity observed in Section 2. ${ }^{13}$ Point 1 of the Crowding Hypotheses is therefore confirmed.

Agents' reciprocity that has been robustly observed in all other experiments discussed so far, is - in the Incentive treatment -, considerably weakened. Principals still appeal to reciprocity by offering the higher rent the higher the demanded effort is (compare (1) and (2) in Table 6), but agents - relative to the Trust-treatment - only weakly (but significantly) reciprocate. The offered rent, which was of great importance for actual effort choices in all treatments so far, has only a weak impact for voluntary effort choices above the selfishly rational effort level.

\footnotetext{
${ }^{12}$ To classify an effort choice as "reciprocal", one has to fix what is in the immediate self-interest of the reciprocator. In all previous two-stage experiments the agent always had - at least in the stage game - an incentive to choose the lowest effort $e=e^{*}=0.1$. The use of fines leads to $e^{*} \geq 0.1$, which is now the correct benchmark for evaluating (reciprocal) effort choices. Notice further that our measure of generosity, the offered rent, is not affected by the use of a fine, which only determines what is in the employee's best material interest (i.e., $\left.e^{*}\right)$. Therefore, the fine is not included as a separate regressor.

${ }^{13}$ Notice that the dependent variable is now $e-e^{*}$ (which is $e-0.1$ in the Trust-treatment). If we estimate (3) with $e$ as the dependent variable, the estimated coefficient of the variable $r$ is 0.018 , which is slightly lower than - but within keeping to - the estimated coefficient in model (2) of Table 3.
} 
TABLE 6: Crowding out of reciprocity through incentive contracts

\begin{tabular}{|c|c|c|c|c|}
\hline \multirow{2}{*}{$\begin{array}{l}\text { Dependent } \\
\text { variables } \\
\text { Explanatory } \\
\text { variables: }\end{array}$} & \multicolumn{2}{|c|}{$\begin{array}{c}\text { offered rent } \\
r\end{array}$} & \multicolumn{2}{|c|}{$\begin{array}{l}\text { actual effort deviation } \\
\qquad e-e^{*}\end{array}$} \\
\hline & $\begin{array}{c}\text { trust } \\
(1)\end{array}$ & $\begin{array}{c}\text { incentive } \\
\text { (2) }\end{array}$ & $\begin{array}{l}\text { trust } \\
(3)\end{array}$ & $\begin{array}{c}\text { Incentive } \\
(4)\end{array}$ \\
\hline Constant & \multicolumn{2}{|c|}{$\begin{array}{l}-1.615 \\
(2.233)\end{array}$} & \multicolumn{2}{|c|}{$\begin{array}{c}0.006 \\
(0.0124)\end{array}$} \\
\hline $\begin{array}{l}\text { êxtreat- } \\
\text { ment }\end{array}$ & $\begin{array}{l}34.010^{* * *} \\
\quad(2.712)\end{array}$ & $\begin{array}{l}29.898^{* * *} \\
(5.262)\end{array}$ & - & - \\
\hline $\begin{array}{l}\text { rxtreat- } \\
\text { ment }\end{array}$ & - & - & $\begin{array}{c}0.013 * * * \\
(0.0008)\end{array}$ & $\begin{array}{c}0.004 * * * \\
(0.0012)\end{array}$ \\
\hline $\mathrm{N}$ & \multicolumn{2}{|c|}{644} & \multicolumn{2}{|c|}{636} \\
\hline Log-L & \multicolumn{2}{|c|}{$-2346.1 * * *$} & \multicolumn{2}{|c|}{$90.3^{* * *}$} \\
\hline$\chi^{2}$ & \multicolumn{2}{|c|}{266.5} & \multicolumn{2}{|c|}{288.2} \\
\hline
\end{tabular}

Note: Since our dependent variables are censored below and above the estimation procedure is censored regression. Since data are not independent within a session we calculate robust standard errors with session as the independent units ( 9 sessions). Standard errors are in parentheses. ${ }^{*}$ denotes significance at the 10-percent level, ** at the 5-percent level and $* * *$ at the 1-percent level. $\hat{e}$ denotes demanded effort, $c(\hat{e})$ are the implied effort costs (see Table 1), $r$ denotes the offered rent (i.e., $w-c(\hat{e})) . e^{*}$ denotes the individually and selfishly rational effort according to the incentives set by $f$ and $\hat{e}$. The independent variables are interaction variables of $\hat{e}$ (and $r$ resp.) and respective treatment dummies. In the trust treatment $e^{*}=0.1$. In total 8 offers were rejected. Data source: Fehr and Gächter (2000) and own calculations.

At the individual level only one out of 32 agents exhibits a significantly positive correlation between the offered rent and $\left(e-e^{*}\right)$ ! This is in stark contrast to the Trusttreatment, where roughly 60 percent of the subjects exhibit a significantly positive renteffort relationship (according to Spearman rank correlations). Indeed, a further data analysis shows that in the Incentive-treatment high effort levels (i.e., those above 0.4) are chosen only in about 14 percent of all cases. In contrast, in the Trust-treatment about 35 percent of effort choices are at least 0.5 . Taken together, these results show that reciprocity has been "crowded out" to a considerable degree by the incentive contracts.

The overall efficiency effects of incentive contracting - as measured by the average performance - are negative as well. Table 7 shows that the effort levels, both the demanded and the actual one, are higher in the Trust-treatment than in the Incentive-treatment. In the Incentive-treatment actual effort levels are even lower than predicted by standard economic theory. This implies that in our setup relying on trust and reciprocity induces at least as high a performance as using incentive contracts. 
TABLE 7: Contractual behavior in trust and incentive contracts - Summary statistics

\begin{tabular}{cccc}
\hline & wage & $\begin{array}{c}\text { effort } \\
\text { demanded } \hat{\boldsymbol{e}}\end{array}$ & $\begin{array}{c}\text { actual } \\
\text { effort } \boldsymbol{e}\end{array}$ \\
\cline { 2 - 4 } Trust treatment & 28.1 & 0.63 & 0.35 \\
Incentive treatment & $(17.4)$ & $(0.26)$ & $(0.25)$ \\
& 19.8 & 0.48 & 0.27 \\
& $(12.8)$ & $(0.16)$ & $(0.17)$ \\
\hline
\end{tabular}

Note: Entries are averages over all twelve periods. Numbers in parentheses are standard deviations. Source: Fehr and Gächter (2000) and own calculations.

This experiment has demonstrated that financial incentives can have detrimental effects on voluntary cooperation. The question arises whether this finding is a general property of incentive systems or just the result of the particular one studied here. This is a topic for future research. However, the findings in Anderhub, Gächter, and Königstein (1999), who study return sharing as an incentive device in a simple principal-agent game, suggest that there are incentive systems, which leave voluntary cooperation intact.

\section{Summary and Discussion}

In this paper we have provided a synoptic investigation of the empirical importance and comparative merits of four remedies of contractual incompleteness discussed in the literature, namely, (1) reciprocity-based voluntary cooperation, (2) long-term contracts, i.e., repeated interactions, (3) social embeddedness, and (4) incentive contracts. We summarize our findings as follows:

1. In line with previous research and arguments about the importance of fair wages and gift exchanges advanced in the literature (e.g., by Akerlof (1982)), we find that both at the aggregate as well as at the individual level a reciprocal motivation can be a suitable contract enforcement device even in the absence of any extrinsic incentives. Its effectiveness, however, depends on the details of the interaction.

2. A repeated interaction strongly mitigates the contract enforcement problem. In a certain sense, the possibility of a repeated interaction "crowds in" reciprocity (by generating a steeper reciprocal relationship than in one-shot encounters). At the individual level we find that many individuals who would act selfishly in the absence of repeated game incentives, imitate reciprocity in a repeated game. Hence, a long-term relationship is a very suitable contract enforcement device because it combines in a natural way standard economic incentives with the power of reciprocity that is even strengthened by them.

3. Social approval incentives turned out to be rather weak in our experiments. They were, independently, not able to contribute significantly to a higher performance. 
4. Whereas the previous institutional arrangements provide rather favorable conditions for improved efficiency, incentive contracts have "crowded out" reciprocity and led to a high degree of opportunistic behavior. We see this as evidence that the introduction of pecuniary incentives into a reciprocal relationship bears "hidden costs" in the sense that it may weaken total incentives for effort provision.

Our results show an interesting parallel to recent findings on the subtleties of "intrinsic motivation", which can be defined as pursuing a particular activity for its own sake, without an apparent reward (see, e.g., Deci, Koestner and Ryan (1999) and Frey (1997)). Therefore, intrinsic motivation for the task may also help to mitigate the contract enforcement problem.

The issue of financial incentives in employment relations has recently received a lot of attention both among practitioners (see, e.g., "The Economist" (1999) or Kohn (1993)) as well as among academics (see, e.g., Frey (1997)). In psychology, there is a debate over possible detrimental effects of incentives on "intrinsic work motivation", where some contend that incentives can lead to a "crowding out" of intrinsic motivation (see, e.g., Deci, Koestner and Ryan (1999), whereas others cast doubt on such findings (e.g., Eisenberger and Cameron (1996)).

In our context, we refer to reciprocity as an intrinsic motivation because we see it as an innate psychic willingness to respond in kind. In the described experiments, the experimental task of an effort choice may be motivated by the intrinsic motivation of reciprocity although it is an artificial task which as such is most likely not done for any intrinsically satisfying reason.

We have just seen that the effectiveness of the intrinsic motivation of reciprocity depends crucially on the compatibility with extrinsic incentives. As, e.g., Frey (1997) shows, something similar holds for 'intrinsic work motivation'. Extrinsic incentives, like monetary rewards or the type of command an employer uses to enforce compliance, may interact adversely with the intrinsic work motivation. For example, a "crowding out effect" may occur if monetary incentives are used to motivate a task that once has been done without pecuniary incentives. Once monetary incentives are used, the task is only exerted for money and not for its own sake anymore. Similar crowding out effects can be observed by using "hard regulations" (Frey (1997), chap. 4)), like a punishment for non-compliance. The hard regulation is an external intervention that may be perceived as being controlling and undermining self-determination. With the intrinsic motivation of reciprocity, signalling distrust by threatening with a 'stick' may have similar psychological effects and lead to the observed "crowding out of reciprocity" through incentive contracts discussed in the previous section.

"Crowding in" in the sense of improved performance is also possible. Enhanced possibilities for reciprocal exchanges 'crowd in' reciprocal behavior and improve contractual performance. In intrinsic work motivation, a "crowding in" may occur if the external intervention is perceived as being supportive. This, for example, is the case if in a work relationship an agent is not given an honor or a prize for a particular task (which 
would tend to crowd out intrinsic motivation) but for his general dedication or performance (see Frey (1997, Chap. 10). In this case, it is more like a 'gift' and it may increase intrinsic work motivation and performance, not least because of triggered reciprocity.

The important point with both intrinsic work motivation and reciprocity-based voluntary cooperation is how agents perceive the contractually incompletely regulated situation (see, e.g., Rousseau (1995) and the discussion in Gneezy and Rustichini (2000)). If agents perceive an extrinsic incentive as supportive there are no detrimental effects of extrinsic incentives. In our context, this seems to be the case with repeated game incentives, where the strategic incentives are perceived as complementary to motivational reciprocity. Introducing a financial incentive for a particular performance may change the perceived situation from one that is based on "good will" and the voluntary exchange of favors (or on intrinsic motivation for the task) to a relationship that is by and large "monetized": You get what you pay for - at the expense of intrinsic motivation or "good will".

In summary, reciprocity and the intrinsic motivation for a particular task (i.e., intrinsic work motivation) share similar features in their interplay with extrinsic incentives. The 'trick' is to combine intrinsic and extrinsic incentives in contractual and institutional designs such that the extrinsic incentives respect the psychology that underlies reciprocity. 


\section{References}

Akerlof, George (1982): Labor Contracts as a Partial Gift Exchange. Quarterly Journal of Economics, 97, 543-569.

Anderhub, Vital, Simon Gächter and Manfred Königstein (1999): Efficient Contracting and Fair Play in a Simple Principal-Agent Experiment. Working Paper No. 18, Institute for Empirical Research in Economics, University of Zurich.

Axelrod, Robert (1984): The Evolution of Cooperation. New York: Basic Books.

Baker, George, Michael Jensen and Kevin Murphy (1988): Compensation and Incentives: Practice vs. Theory. Journal of Finance, XLII, 593-616.

Bewley, Truman (1999): Why Wages Don't Fall During a Recession. Cambridge: Harvard University Press.

Blau, Peter (1964): Exchange and Power in Social Life. New Brunswick: Transaction Publishers.

Bohnet, Iris (1997): Kooperation und Kommunikation. Eine ökonomische Analyse individueller Entscheidungen. Tübingen: J.C.B. Mohr (Paul Siebeck).

Bolton, Gary and Axel Ockenfels (2000): ERC-A Theory of Equity, Reciprocity, and Competition. American Economic Review, 90(1), 166-193.

Deci, Edward, Richard Koestner, and Richard Ryan (1999): A Meta-Analytic Review of Experiments Examining the Effects of Extrinsic Rewards on Intrinsic Motivation. Psychological Bulletin, 125(6), 627-668.

Dufwenberg, Martin and Georg Kirchsteiger (2000): Reciprocity and Wage Undercutting. European Economic Review, 44(4-6), 1069-1078.

The Economist (1999). A Survey of Pay. May 8, 1999.

Eisenberger, Robert and Judy Cameron (1996). Detrimental Effects of Reward. Reality or Myth? American Psychologist, 51, 1153-1166.

Falk, Armin and Urs Fischbacher (1999): A Theory of Reciprocity. Working Paper No. 6, Institute for Empirical Research in Economics, University of Zurich.

Falk, Armin, Simon Gächter, and Judith Kovács (1999): Intrinsic motivations and extrinsic incentives in a repeated game with incomplete contracts. Journal of Economic Psychology 20, 251-284.

Fehr, Ernst, Simon Gächter, and Georg Kirchsteiger (1997): Reciprocity as a Contract Enforcement Device - Experimental Evidence. Econometrica, 65(4), 833-860.

Fehr, Ernst, and Simon Gächter (2000): Do Financial Incentives Crowd out Voluntary Cooperation? Working Paper No. 34, Institute for Empirical Research in Economics, University of Zurich.

Fehr, Ernst, Georg Kirchsteiger, and Arno Riedl (1993): Does Fairness prevent Market Clearing? An Experimental Investigation. Quarterly Journal of Economics, 108, 437460.

Fehr, Ernst and Klaus Schmidt (1999): “A Theory of Fairness, Competition and Cooperation", Quarterly Journal of Economics, 114, 817-868.

Frey, Bruno (1997): Not Just For the Money. An Economic Theory of Personal Motivation. Cheltenham: Edward Elgar Publishing.

Gächter, Simon and Armin Falk (1999): Reputation or Reciprocity?, Working Paper No. 19, Institute for Empirical Research in Economics, University of Zurich. 
Gneezy, Uri and Aldo Rustichini (2000): A fine is a price. Journal of Legal Studies, 29, 117.

Gouldner, Alvin (1960): The Norm of Reciprocity. American Sociological Review, 25, 161-178.

Granovetter, Mark (1992): 'The Sociological and Economic Approaches to Labour Market Analysis: A Social Structural View'. In: Mark Granovetter and Richard Swedberg (eds.), The Sociology of Economic Life (pp. 233-263). Boulder: Westview Press.

Güth, Werner (1994): Distributive Justice. A Behavioural Theory and Empirical Evidence. In: Hermann Brandstätter and Werner Güth (eds). Essays on Economic Psychology (pp. 153-156). Berlin: Springer.

Kohn, Alfie (1993): Why Incentive Plans Cannot Work. Harvard Business Manager, Sept.Oct., 54-63.

Lazear, Edward (1991): Labour Economics and the Psychology of Organizations. Journal of Economic Perspectives, 5(2), 89-110.

Leibenstein, Harvey (1979): A Branch of Economics is Missing: Micro-Micro Theory. Journal of Economic Literature, XVII, 477-502.

MacLeod, Bentley and James Malcomson (1998): Markets and Motivation. American Economic Review 88 (3), 388-411.

Milgrom, Paul and John Roberts (1992): Economics, Organization and Management. New Jersey: Prentice Hall International.

Prendergast, Canice (1999): The Provision of Incentives in Firms. Journal of Economic Literature, 37, 7-63.

Rabin, Matthew (1993): Incorporating Fairness into Game Theory and Economics. American Economic Review, 83(5), 1281 - 1302.

Rousseau, Denise (1995). Psychological Contracts in Organizations. Understanding Written and Unwritten Agreements. Thousand Oaks: SAGE Publications.

Schlicht, Ekkehart (1998): On Custom in the Economy. Oxford University Press.

Simon, Herbert (1991): Organizations and Markets. Journal of Economic Perspectives, $5(2), 25-44$.

van Dijk, Frans, Joep Sonnemans, and Frans van Winden (forthcoming): Incentive Systems in a Real Effort Experiment, European Economic Review.

Williamson, Oliver (1985): The Economic Institutions of Capitalism. New York: Free Press. 